\title{
Artikel
}

\section{Toezicht op de vereffening door de rechter met bijzondere aandacht voor proces- rechtelijke aspecten en eenduidigheid}

\author{
Mr. drs. J.H. Lieber*
}

\section{Inleiding}

Voor een goed begrip van de regeling van het toezicht door de rechter op de vereffening moeten we kennisnemen van de antwoorden van de Tweede Kamer op de vragen van Meijers in de zogeheten Vraagpuntenprocedure. Ik neem u mee terug naar het parlementaire jaar 1952-1953. Het gaat om de vraagpunten 41 en 42. De Tweede Kamer concludeerde destijds als volgt:

'41. Het is gewenst de vereffening van nalatenschappen meer dan thans onder controle van de rechter door deze benoemde vereffenaars te doen geschieden. De benoeming van vereffenaars worde slechts dan toegelaten, wanneer de erfgenaam dit verzoekt of een schuldeiser daarvoor bijzondere, in de wet te noemen, gronden kan aanvoeren.'

'42. De bemoeienissen, die verband houden met de verdeling en vereffening van nalatenschappen en andere boedels, moeten in plaats van aan de gewone rechter worden opgedragen aan een bijzondere rechter (de boedelrechter). De boedelrechter blijve overigens lid van de gewone rechterlijke macht.'2

* Mr. drs. J.H. Lieber is senior raadsheer bij het Gerechtshof ArnhemLeeuwarden en het Gerechtshof Amsterdam.

1. Parl. Gesch. Boek 4 BW (Vaststellingswet), p. xxxvi.

2. Parl. Gesch. Boek 4 BW (Vaststellingswet), p. xxxix.
Ik lees deze antwoorden tegen de achtergrond van het oude erfrecht. Daarin waren de bemoeienissen die verband hielden met de vereffening en verdeling van nalatenschappen verdeeld over de kantonrechter en de rechtbank. Die regeling behoefde wijziging wegens de willekeur die daarbij heerste, omdat nu eens de kantonrechter, dan weer de rechtbank bevoegd was. De rol van de rechter bij verdelingen was in het oude recht bovendien beperkt; de hoofdrol was voor de notaris. Men zie de artikelen 696 en 697 van het Wetboek van Burgerlijke Rechtsvordering (Rv) (oud).

Ik merk op dat in de vraagpunten sprake is van controle en bemoeienissen enerzijds en van benoeming anderzijds, een tweedeling die we straks nog zullen terugzien.

De rest is bekend: de conclusies van de Tweede Kamer zijn uitgemond in afdeling 3 van titel 6 van Boek 4 van het Burgerlijk Wetboek (BW) met het opschrift 'Vereffening van de nalatenschap'. Ook de afdelingen 1 en 2 van die titel bevatten trouwens bepalingen die voor het toezicht door de (kanton)rechter van belang zijn. Ik noem: artikel 4:185 lid 2 (maatregelen van de kantonrechter gedurende de termijn van beraad op verzoek van en in het belang van een belanghebbende), artikel 4:191 lid 2 (maatregelen van de kantonrechter nodig voor het behoud van goederen, zolang niet alle erfgenamen hebben aanvaard) en artikel 4:199 lid 2 BW (de verplichte mededeling aan de kantonrechter dat het saldo van een beneficiair aanvaarde nalatenschap negatief is). De boedelrechter is er uiteindelijk tot spijt van velen niet gekomen; zijn plaats is ingenomen door de oude en vertrouwde kantonrechter. 
In deze bijdrage staan drie vragen centraal:

- Heeft de wetgever een effectief toezicht door de rechter tijdens de vereffening mogelijk gemaakt?

- Hoe geeft de rechter uitvoering aan zijn toezichthoudende taak?

- Speelt de verdelingsrechter een rol bij de vereffening?

Ik zal bij het antwoord op deze vragen telkens aandacht geven aan het thema van deze professionele ontmoeting: 'eenduidigheid'. 3

\section{Heeft de wetgever een effectief toezicht door de rechter tijdens de vereffening mogelijk gemaakt?}

Ik schets in dit onderdeel kort hoe de wetgever het toezicht op de vereffening heeft vormgegeven en plaats daar enkele kanttekeningen bij.

\subsection{Het systeem van toezicht}

Het systeem dat de wetgever heeft ontworpen voor de vereffening roept het beeld op van een mengpaneel, ${ }^{4}$ waarbij de rechtbank en de kantonrechter samen de schuiven bedienen en soms ook de rechter-commissaris (art. 4:208 BW) meeschuift.

Zo kan de rechtbank een vereffenaar benoemen, al dan niet na een beneficiaire aanvaarding (zie art. 4:203 t/m 4:205 BW). Door zo'n benoeming zet de rechtbank de schuif naar de zware vereffening helemaal open; wijst de rechtbank het verzoek tot benoeming af, dan blijft de schuif staan op geen vereffening of - indien beneficiair is aanvaard - op de lichte vereffening. Daarna is de kantonrechter aan zet, of beter gezegd aan schuif. Heeft de rechtbank de vereffenaar benoemd, dan kan de kantonrechter de schuif die op de zware vereffening is komen te staan vervolgens weer iets naar beneden verplaatsen door de vereffenaar vrij te stellen van de verplichting de rekening en verantwoording en de uitdelingslijst neer te leggen. Lees artikel 4:221 lid 2 BW.

Wijst de rechtbank het verzoek een vereffenaar te benoemen af en is de nalatenschap beneficiair aanvaard, dan valt er voor de kantonrechter nog wel wat te schuiven. Hij kan de schuif van lichte vereffening op geen vereffening zetten. Zie daarvoor artikel 4:202 lid 2 BW over het verzoek een wettelijk vertegenwoordiger van een erfgenaam te ontheffen van de verplichting te veref-

3. Voor de voorbereiding heb ik rechtstreeks gesproken met Marleen Aalderink en indirect met Tanja Steenland, die zich beiden bij de Rechtbank Gelderland bezighouden met de vereffening van nalatenschappen. Ik heb veel geleerd van hun praktische en nuttige opmerkingen.

4. Zoals dat bijvoorbeeld wordt gebruikt bij de opnames van muziek of bij concerten. fenen (art. 4:202 lid 2 BW). Zie ook artikel 4:209 lid 1 en 2 BW over het verzoek kosteloze vereffening of opheffing van de vereffening te bevelen (art. 4:209 lid 1 en 2 BW). De kantonrechter kan verder de schuif van de lichte vereffening iets naar beneden verplaatsen door erfgenamen die beneficiair hebben aanvaard te ontheffen van de verplichting de boedelbeschrijving ter inzage te leggen (art. 4:211 lid 4 BW). Hij kan de schuif ook van de lichte vereffening iets naar boven verplaatsen door te bepalen dat erfgenamen toch een lijst van erkende en betwiste vorderingen en de rekening en verantwoording en de uitdelingslijst moeten neerleggen (art. 4:221 lid 1 BW). De kantonrechter moet zich daarbij laten leiden door de omvang van de nalatenschap en de belangen van eerst de schuldeisers en dan pas de erfgenamen. ${ }^{5}$

Dit systeem maakt het voor de rechter mogelijk de vereffening op maat te snijden. De wet werkt dat nog verder uit en verschaft zowel de rechtbank als de kantonrechter nog meer instrumenten. Ik laat nu de rechtercommissaris gemakshalve buiten beschouwing. Zo kan de rechtbank bij de benoeming van een vereffenaar van deze waarborgen verlangen (art. 4:206 lid 2 BW) en hem bijvoorbeeld verplichten voor bepaalde handelingen toestemming te vragen aan de kantonrechter of de boedelnotaris. ${ }^{6}$ Ook kan de rechtbank twee of meer vereffenaars benoemen en bij de benoeming een verdeling van de werkzaamheden treffen (art. 4:206 lid 2 BW). De rechtbank kan ook al dan niet ambtshalve vereffenaars schorsen en ontslaan en in verband daarmee voorlopige voorzieningen treffen (art. 4:206 lid $5 \mathrm{BW}$ ).

En ook de kantonrechter krijgt van de wetgever nog een heel takenpakket, dat soms overlap laat zien met dat van de rechtbank. Een korte opsomming:

- Hij beslist op geschillen tussen erfgenamen die beneficiair hebben aanvaard en de executeur, met als mogelijk gevolg dat de lichte vereffening van toepassing kan worden (art. 4:202 lid 1 onder a slot BW).

- Hij kan werkzaamheden tussen de vereffenaars verdelen (art. 4:206 lid 2 BW).

- Hij stelt het loon van de vereffenaar vast vóór het opmaken van de uitdelingslijst (art. 4:206 lid 3 BW).

- Hij kan aanwijzingen geven en inlichtingen vragen (art. 4:210 lid $1 \mathrm{BW}$ ).

- Hij kan machtiging geven aan erfgenamen om over goederen van de nalatenschap of hun aandeel daarin te beschikken (art. 4:211 lid 2 BW).

- Hij bepaalt de datum voor de oproeping van schuldeisers (art. 4:214 lid $1 \mathrm{BW}$ ).

- Hij beslist op geschillen over tegeldemaking van goederen (art. 4:215 lid $2 \mathrm{BW}$ ).

- Hij kan de termijn voor het neerleggen van de rekening en verantwoording en de uitdelingslijst verlengen (art. 4:218 lid $1 \mathrm{BW}$ ).

5. Zie Parl. Gesch. Boek 4 BW (Vaststellingswet), p. 945-946. Zie ook HR 17 mei 2013, ECLI:NL:HR:2013:BZ3643, NJ 2013/488.

6. Parl. Gesch. Boek 4 BW (Vaststellingswet), p. 988. 
- Hij beslist op verzet tegen de uitdelingslijst (art. 4:218 lid 3 en 5 BW).

- Hij kan op verzoek van de vereffenaar beslagen opheffen (art. 4:223 lid 4 BW).

2.2 Kanttekeningen bij het systeem van toezicht Ik mis in dit systeem de mogelijkheid voor de kantonrechter om de rechtbank te verzoeken een vereffenaar te benoemen, in het bijzonder voor het geval de nalatenschap negatief is. De kantonrechter die op de hoogte raakt van een negatieve nalatenschap, kan zoals gezegd maatregelen voorschrijven ter behoud van de goederen van de nalatenschap (art. 4:191 lid $2 \mathrm{BW}$; zie ook art. 4:185 lid 2 BW). Hij kan, als de nalatenschap beneficiair is aanvaard, aanwijzingen geven (art. 4:210 lid 1 BW), zelfs de aanwijzing dat de erfgenamen een verzoek moeten doen om benoeming van een vereffenaar. Maar wat als die aanwijzing niet wordt gevolgd? Ik meen dat het, voor het geval niemand om benoeming van een vereffenaar verzoekt, uit de eis van effectief toezicht in het belang van de schuldeisers voortvloeit dat de kantonrechter dit verzoek kan doen. Zou de kantonrechter niet als belanghebbende in de zin van artikel 4:203 en 4:204 BW zijn aan te merken, dan is wetswijziging in deze zin gewenst. $^{7}$

De volgende vraag is of de verdeling van taken over de rechtbank en de kantonrechter effectief toezicht in de weg staat. In de praktijk en in de literatuur wordt veel gemopperd over de verdeling van de taken tussen de rechtbank en de kantonrechter. Men pleit ervoor de kantonrechter over de hele linie bevoegd te maken of alsnog de boedelrechter in te voeren. ${ }^{8}$ Ik merk op dat de wetgever, zo blijkt uit de parlementaire geschiedenis, de keuze voor twee rechters bewust heeft gemaakt. ${ }^{9}$ Heel kort gezegd: de kantonrechter beslist in het kader van zijn toezichthoudende taak bij uitvoeringskwesties; de rechtbank neemt de meer principiële beslissingen. In concreto betekent dit dat de rechtbank benoemt en de kantonrechter controleert en zich met de uitvoering van de vereffening en de fijnafstemming (licht + of zwaar -) bemoeit. Een concreet voornemen om de wet op dit punt te wijzigen, is mij niet bekend. De praktijk zal zich er dus voorlopig mee moeten behelpen dat hier de gewenste eenduidigheid blijft ontbreken.

Nu horen de kantonrechter en de rechtbank tot hetzelfde gerecht, al bewonen zij andere kamers. Ze zijn als het ware voordeurdelers en buren in hetzelfde huis en kunnen in het kader van goed naoberschap samenwerken. Voor zover dat al niet gebeurt, verdient het aanbeveling de werkzaamheden rond de vereffening binnen de rechtbank inclusief de afdeling kanton door dezelfde personen (rechters, juridisch medewerkers en griffie/

7. Zie hierover ook J.B. Vegter, Grondslagen der beneficiaire aanvaarding naar Nederlands en Duits recht (diss. Leiden), 1989, p. 234-237.

8. Zie bijvoorbeeld A.H.N. Stollenwerck, Vereffening van de nalatenschap, in: B.F.P. Lhoëst \& N.J.M. Sjerps (red.), Nieuw erfrecht in de praktijk (preadviezen KNB), Den Haag: Sdu Uitgevers 2006, p. 234-237 en Vegter 1989, p. 240 en stelling 6 bij zijn proefschrift.

9. Parl. Gesch. Boek 4 (Vaststellingswet), p. 877 e.v. administratie) te doen plaatsvinden in een gezamenlijk cluster erfrecht. Zaken waarin zowel een verzoek aan de rechtbank als een verzoek aan de kantonrechter is gedaan (denk aan benoeming vereffenaar en ontslag executeur), kunnen op een gecombineerde mondelinge behandeling plaatsvinden door één rechter met twee petten. Dat bevordert ondanks de verdeling van taken over verschillende rechters toch zo veel mogelijk een eenduidig en effectief toezicht.

Ik wijs hier ook vol hoop op het consultatievoorstel Experimentenwet rechtspleging. ${ }^{10}$ Dit wetsvoorstel biedt een wettelijke grondslag om te experimenteren met innovatieve gerechtelijke procedures. Bij algemene maatregel van bestuur zal bij wijze van experiment kunnen worden afgeweken van de wetgeving die gaat over de toegang tot en de rechtspraak door de burgerlijke rechter. Doel is daardoor de eenvoud, snelheid, flexibiliteit en effectiviteit bij gerechtelijke procedures te dienen. Wat zou het mooi zijn als het erfrecht zou mogen experimenteren met een regeling die inhoudt dat alle erfrechtelijke geschillen, ook dagvaardingszaken, op verzoek door de kantonrechter worden behandeld en beslist. Dat zou de eenduidigheid zeker ten goede komen.

Bij de bestudering van het systeem rees bij mij de vraag hoe de (kanton)rechter weet dat een nalatenschap wettelijk moet worden vereffend? Dat te weten is toch wel de minimumeis voor effectief toezicht. Het systeem werkt zo dat de rechtbank en de kantonrechter pas aan de knoppen kunnen gaan draaien als er een verzoek of een mededeling inkomt die te maken heeft met vereffening. Zo moeten erfgenamen die vereffenaars zijn de kantonrechter melden dat de schulden de baten overtreffen (art. 4:199 lid 2 BW) en dat het adres van een schuldeiser onbekend is gebleven (art. 4:214 lid 2 BW). Verder kunnen zij geschillen met de executeur over de omvang van de nalatenschap voorleggen aan de kantonrechter (art. 4:202 lid 1 onder a BW). Is dat alles niet het geval, dan komen zij niet in aanraking met de kantonrechter. Zolang de nalatenschap positief is en de schuldeisers bekend zijn, is dat niet zo erg. Hier ontstaat wel een probleem als erfgenamen-vereffenaars ten onrechte deze mededelingen achterwege laten. In dat geval is toezicht van de kantonrechter in het belang van de schuldeisers dringend gewenst, maar komt toch niet tot stand. Hier voorziet het systeem dan ook niet in effectief toezicht. Dat de schuldeisers zich in zo'n geval kunnen verhalen op het eigen vermogen van de erfgenamen biedt slechts troost als daar ook iets te halen is. De oplossing is dat de kantonrechter actief het boedelregister raadpleegt om te zien of een nalatenschap beneficiair is aanvaard. Maar is hij op die taak berekend en wil hij wel zo actief zijn? En hoe staat het met nalatenschappen die als beneficiair aanvaard hebben te gelden op grond van de wet en het boedelregister zwijgt (art. 4:193 lid 2 BW)?

10. Zie het conceptwetsvoorstel Experimentenwet rechtspleging en de ontwerp-memorie van toelichting op https://www.internetconsultatie.nl/ experimenten. 
Hoe komt de kantonrechter daarachter als de wettelijk vertegenwoordiger stilzit (art. 4:193 lid 1 BW)?

En hoe is dat geregeld bij de benoeming van een vereffenaar door de rechtbank? Is de kantonrechter daarvan op de hoogte? Raadpleegt hij daartoe dagelijks het boedelregister of de Staatscourant? Toevoeging van één zin aan artikel 4:206 lid $6 \mathrm{BW}$ zou dat probleem kunnen oplossen: 'De griffier doet van de benoeming van de vereffenaar onverwijld mededeling aan de kantonrechter.' Zo wordt voorkomen dat de kantonrechter pas van de wettelijke vereffening weet krijgt als de vereffenaar hem om vaststelling van zijn loon vraagt. Dat laatste komt in de praktijk regelmatig voor.

Mijn slotsom is dat de wet in beginsel effectief toezicht mogelijk maakt, maar dat er op onderdelen nog wel verbeteringen nodig zijn. Hamvraag daarbij blijft: hoe actief wil of kan de rechter die toezicht houdt zijn?

\section{Hoe geeft de rechter uitvoering aan zijn toezichthoudende taak?}

De complexiteit van het erfrecht is een gegeven, een axioma zo men wil. Bij de vereffening komen daar nog de raakvlakken met de Faillissementswet $\left(\mathrm{F}_{\mathrm{w}}\right)$ en het insolventierecht bij. ${ }^{11}$ Ook de regeling van het toezicht door de kantonrechter op het vermogen van minderjarigen en de beschermingsmaatregelen voor meerderjarigen kunnen helpen de uitwerking van de regels over vereffening te stroomlijnen. De rechtspraktijk is nog maar pas begonnen aan een exploratie van al deze moeilijke, maar interessante grensgebieden. Voor de toepassing en verdieping van de regels over de wettelijke vereffening valt daar nog heel wat te halen.

Voor de eenduidigheid en een effectieve uitvoering van het toezicht zou het zeer nuttig zijn binnen de rechtbanken (inclusief de afdeling kanton) - als dat al niet is gebeurd - clusters te vormen waarin het toezicht bij de wettelijke vereffening en bij insolventie is gebundeld. De taken van de kantonrechter en de rechter-commissaris lijken immers sterk op elkaar; dat geldt te meer voor de rechter-commissaris in de vereffening (art. 4:208 $\mathrm{BW})$. Een verdere clustering met het toezicht op het vermogen van minderjarigen en meerderjarigen kan de eenduidigheid nog verder bevorderen.

Voor een goede uitvoering van zijn toezicht kan de kantonrechter in het spoor van artikel 73a lid $1 \mathrm{Fw}$ op voet van artikel 4:210 lid $1 \mathrm{BW}$ aan de vereffenaar een aanwijzing geven om telkens na verloop van een bepaalde periode verslag uit te brengen 'over de toestand van de boedel'. In feite geldt die verplichting al indien de veref-

11. Zie heel recent het artikel van J.M. van Anken, Fixatie in faillissement en vereffening, WPNR 2018/7213 en de daar genoemde literatuur. fenaar een tussentijds voorschot op zijn loon vraagt. De Richtlijnen Vereffening nalatenschappen (I.9) verlangen immers in het voetspoor van het Gerechtshof ArnhemLeeuwarden $^{12}$ voor dat geval al dat de vereffenaar tussentijds rekening en verantwoording aflegt.

De rechter was anders dan de notaris tot 2003 niet heel nauw betrokken bij het erfrecht. Inmiddels durf ik wel te zeggen dat hij zijn kennisachterstand grotendeels heeft goedgemaakt, net als de (gespecialiseerde) advocaat.

Verder wijs ik op de rechtersregelingen: de Handleiding erfrechtprocedures kantonrechter (laatste versie 7.0 van 8 oktober 2018) en de Richtlijnen Vereffening nalatenschappen (laatste versie 2.0 van 8 oktober 2018). Dit zijn collectieve rechtersregelingen die 'uniforme rechtstoepassing' beogen (art. 23 lid 3 en 94 van de Wet op de rechterlijke organisatie (Wet RO)). Onder omstandigheden hebben zij de status van recht in de zin van artikel 79 Wet RO. Over eenduidigheid gesproken! Het bestaan van deze dynamische regelingen hebben wij te danken aan de inspanningen van de Expertgroep Erfrecht, die ressorteert onder de Raad voor de rechtspraak.

Eenduidigheid kan ook worden bereikt door het instellen van gewone rechtsmiddelen, het stellen van prejudiciële vragen of door bijzondere rechtsmiddelen als cassatie in het belang der wet. Beslissingen in hoger beroep kunnen sturing geven aan uniformering van de wijze waarop kantonrechters of rechtbanken de vereffening begeleiden. Als voorbeeld noem ik hier nogmaals de beslissing van het Gerechtshof Arnhem-Leeuwarden ${ }^{13}$ over de mogelijkheden voor een voorschot op het loon van de vereffenaar. Die beslissing is vervolgens verwerkt in de Richtlijnen Vereffening nalatenschappen. Een ander mooi voorbeeld is de beslissing van de Hoge $\operatorname{Raad}^{14}$ op een vordering tot cassatie in het belang der wet over de kosteloze vereffening en de opheffing van de vereffening. De Hoge Raad heeft daarbij verwezen naar de Handleiding erfrechtprocedures kantonrechter en die verwijst op haar beurt nu weer naar deze uitspraak.

Er gebeurt dus al heel veel om het toezicht eenduidig te doen zijn. Toch zijn er nog wel significante verschillen.

Ik hoor uit de praktijk van de kantonrechter dat de een zich veel actiever opstelt bij het houden van toezicht en het opsporen van nalatenschappen die onder de wettelijke vereffening vallen dan de ander. Ik verwijs voor de vraag hoe actief de kantonrechter moet of kan zijn naar wat ik al eerder opmerkte. Eenduidigheid in de mate van activiteit mag van mij een punt van aandacht voor de Expertgroep zijn, als het dat al niet is.

In de praktijk blijkt ook dat kantonrechters op verschillende wijze uitvoering geven aan artikel 4:210 lid 1 BW:

12. Hof Arnhem-Leeuwarden 25 augustus 2015, ECLI:NL:GHARL: 2015:7022

13. Hof Arnhem-Leeuwarden 25 augustus 2015, ECLI:NL:GHARL: 2015:7022.

14. HR 4 mei 2018, ECLI:NL:HR:2018:681. 
het geven van aanwijzingen. Deze bepaling is heel belangrijk en staat centraal in de toezichthoudende taak van de kantonrechter. $\mathrm{Nu}$ geeft de ene kantonrechter zijn aanwijzingen op verzoek bij beschikking en zet de griffier onder de beschikking de mededeling dat hoger beroep mogelijk is, ${ }^{15}$ een andere kantonrechter doet dat eenvoudig met een brief. In de Richtlijnen Vereffening nalatenschappen lees ik dat de kantonrechter aanwijzingen kan geven naar aanleiding van concrete verzoeken. In de Handleiding erfrechtprocedures kantonrechter staat dat de kantonrechter op grond van artikel 4:210 lid 1 BW ambtshalve kan optreden, dat aanwijzingen niet in een beschikking worden vastgelegd, en dat hoger beroep niet aan de orde is. Dat laatste lijkt mij juist. ${ }^{16}$ Artikel 4:210 lid 1 BW rept niet van een 'verzoek'. Bij de aard van de aanwijzing als effectief middel van toezicht past niet goed dat daarop de regels van het procesrecht onverkort van toepassing zijn met de mogelijkheid tot aan de Hoge Raad daarover te procederen. Lastige vragen, in rechtspraak ${ }^{17}$ en literatuur ${ }^{18}$ gerezen, als wie zijn in zo'n procedure dan belanghebbenden en heeft de aanwijzing van de kantonrechter gezag van gewijsde tussen de vereffenaar en de belanghebbenden, zijn dan vanzelfsprekend niet aan de orde. Het ware goed in de Richtlijnen Vereffening nalatenschappen met zoveel woorden vast te leggen dat aanwijzingen ambtshalve (al dan niet na een signaal van een betrokkene) kunnen worden gegeven en schriftelijk worden vastgelegd in een brief aan de vereffenaar. Ook hier past eenduidig en effectief optreden.

\section{Mag ook de verdelingsrechter zich met de vereffening bemoeien?}

De regel is: eerst vereffenen, dan pas verdelen (art. 4:222 BW). De reden daarvoor is duidelijk: bij verdeling verdwijnen goederen van de nalatenschap uit de greep van de vereffenaar en de schuldeisers. De regel is niet snoeihard. Heeft de rechter een vereffenaar benoemd, dan kunnen de erfgenamen toch (partieel) verdelen met medewerking van de vereffenaar of vervangende machtiging van de kantonrechter (art. 4:211 lid $2 \mathrm{BW}$ ). Die medewerking of machtiging komt er natuurlijk alleen als daardoor de belangen van de schuldeisers niet in het gedrang dreigen te komen. Hoe zit het als de erfgenamen vereffenaar zijn. Kunnen zij dan als erfgenamen verdelen met medewerking van zichzelf als vereffenaar? Daaraan staat, zo wordt in de

15. Zie bijvoorbeeld Rb. Den Haag (kanton) 1 september 2017, ECLI:NL:RBDHA:2017:9802.

16. Zie (anders) S.R. Baetens, De aanwijzing aan de vereffenaar op grond van artikel 4:210 lid 1 BW, Tijdschrift Erfrecht 2018/2, p. 30-36

17. Rb. Amsterdam 3 augustus 2017, ECLI:NL:RBAMS:2017:5864.

18. Zie Baetens 2018 literatuur $^{19}$ aangenomen, artikel 3:68 BW over de verboden Selbsteintritt in de weg, hetgeen de verdeling nietig maakt. De erfgenamen-vereffenaars kunnen dat probleem oplossen door vervangende machtiging van de kantonrechter te vragen, die ook hier in het bijzonder het belang van de schuldeisers in het oog moet houden.

Tot zover geen probleem. De vereffenaar of de kantonrechter houdt een oogje in het zeil. Het wordt anders als een van de erfgenamen gedurende de vereffening geheel of partieel wil verdelen en de verdelingsrechter op voet van artikel 3:185 $\mathrm{BW}$ vraagt de verdeling vast te stellen of de wijze van verdeling te gelasten. Deze mogelijkheid lijkt afgesneden door de duidelijke tekst van artikel 4:222 BW. Daarin staat immers dat artikel 3:185 BW tijdens de vereffening niet geldt, zodat de rechter niet kan verdelen, sterker nog: er geen toegang tot die rechter mogelijk is. Wie desondanks tijdens de vereffening verdeling vorderde, werd tot voor kort niet-ontvankelijk verklaard. Maar onze hoogste rechter oordeelde anders.

De Hoge Raad $^{20}$ heeft beslist dat ook als de vereffening niet is voltooid, de verdelingsrechter in overleg met partijen moet onderzoeken of er mogelijkheden zijn om toch te verdelen op een wijze die ook voldoende rekening houdt met de belangen van schuldeisers van de nalatenschap. Daarbij kan worden gedacht aan het aanhouden van de zaak totdat alsnog vereffening heeft plaatsgevonden, aan een verdeling onder voorwaarden die de positie van schuldeisers waarborgt, of aan een gedeeltelijke verdeling die de rechten van schuldeisers van de nalatenschap onverlet laat.

De Hoge Raad plooit het op het eerste oog zo onverbiddelijke artikel 4:222 BW en zet de deur naar de verdelingsrechter ook tijdens de vereffening open. Daarmee lijkt de deur naar de kantonrechter in het slot te vallen. Moet de kantonrechter voor de verdeling die de verdelingsrechter heeft vastgesteld of die de erfgenamen op veroordeling van die rechter tot stand gaan brengen nog machtiging verlenen? Daarover spreekt de Hoge Raad zich niet uit. In zijn noot bij dit arrest in NJ 2017/408 bepleit Perrick dat geen machtiging van de kantonrechter meer is vereist, omdat de verdelingsrechter de belangen van de schuldeisers al heeft behartigd. Daarin kan ik niet meegaan. De verdeling door de rechter komt in de plaats van de verdeling door de erfgenamen zelf. Het past in het systeem dat daarvoor de kantonrechter nog zijn machtiging geeft. Bovendien is de beslisnorm van de verdelingsrechter een andere dan die van de kantonrechter. De verdelingsrechter houdt rekening met de belangen van partijen en het algemeen belang (art. 3:185 lid $1 \mathrm{BW})$; de kantonrechter laat zich bovenal leiden door de belangen van de schuldeisers. De kantonrechter beschikt over het instrumentarium om de vereffening te begeleiden, de verdelingsrechter niet, en hij is ook nog

19. S. Perrick, Verdeling gemeenschappelijk goed gedurende vereffening, WPNR 2014/7040. Zie ook de conclusie van A-G Timmermans bij HR 18 maart 2016, ECLI:NL:HR:2016:454.

20. HR 19 mei 2017, ECLI:NL:HR:2017:939. 
eens afhankelijk van wat de deelgenoten hem hebben meegedeeld.

Het is dus onwenselijk dat naast de rechtbank en de kantonrechter nu ook de verdelingsrechter achter het mengpaneel plaatsneemt en mee gaat schuiven. Hoe mooi was het aanvankelijk in het ontwerp-NBW geregeld. Daarin was zowel het toezicht op de vereffening als de verdeling in handen van de boedelrechter gelegd, die op daartoe gedaan verzoek van de meest gerede partij besliste. Was dat maar zo gebleven, dan zat er nu maar één rechter aan de knoppen. Dat is pas eenduidigheid. 